\title{
Indium In 111-DOTA-exendin-4
}

National Cancer Institute

\section{Source}

National Cancer Institute. Indium In 111-DOTA-exendin-4. NCI Thesaurus. Code

C115981.

A radiopharmaceutical composed of the glucag on-like peptide 1 receptor (GLP-1R) agonist exendin-4 linked by the macrocyclic chelator 1,4,7,10-tetraazacyclododecane1,4,7,10-tetraacetic acid (DOTA) to the positron-emitting radionuclide indium In 111, with potential use in diagnostic imaging upon positron emission tomography (PET). Upon administration of indium In 111-DOTA-exendin-4, the exendin-4 moiety binds to GLP-1R and is subsequently internalized. The radionuclide moiety can be detected using PET and GLP-1R-expressing tumors can be localized. GLP-1R, located on beta cells, is overexpressed on insulinomas, which are insulin-secreting neuroendocrine tumors. 